\title{
Prevalence of soil transmitted helminths and impact of Albendazole on parasitic indices in Kotto Barombi and Marumba II villages (South-West Cameroon)
}

\author{
L. Nkengazong ${ }^{1}$, F. Njiokou ${ }^{1 *}$, S. Wanji ${ }^{2,3}$, F. Teukeng ${ }^{1}$, P. Enyong ${ }^{2}$ and T. Asonganyi ${ }^{4}$ \\ ${ }^{1}$ Department of Animal Biology and Physiology, Faculty of Science, P.O. Box 812, Yaounde, University of Yaounde I, \\ Cameroon. \\ ${ }^{2}$ Research Foundation of Tropical Diseases and Environment, P.O. Box 474 Buea, Cameroon. \\ ${ }^{3}$ Department of Biochemistry and Microbiology, Faculty of Science, University of Buea, P.O. Box 63, Buea, Cameroon. \\ ${ }^{4}$ Faculty of Medicine and Biomedical Science, University of Yaounde I, Cameroon.
}

Accepted 20 January, 2010

This study assessed the actual prevalence of geohelminths and the impact of albendazole on parasitic indices in Kotto Barombi and Marumba II. Stools samples were collected from 420 school children and examined using the Kato-katz faecal technique. Participants were treated with $600 \mathrm{mg}$ of albendazole. Baseline prevalence of infections and mean parasite loads were $26.4 \%$ and $6226.9 \mathrm{e} / \mathrm{g}$ (Ascaris lumbricoides), $31.0 \%$ and $252.4 \mathrm{e} / \mathrm{g}$ (Trichuris trichiura), and $1.4 \%$ and $468.0 \mathrm{e} / \mathrm{g}$ (Necator americanus). Four children $(0.9 \%)$ were infected with Strongyloides stercoralis. A significant difference of prevalence was observed between the two villages for $A$. lumbricoides $(P=0.0001)$ and $T$. trichiura $(P=0.0005)$, and parasite loads for $T$. trichiura $(P=0.0001)$. Single infection $(T$. trichiura or $A$. lumbricoides) and double infection (A. lumbricoides - T. trichiura) were more prevalent. Post treatment control showed a decrease of prevalence and mean parasite load to $24.4 \%$ and $2969.5 \mathrm{e} / \mathrm{g}$ (A. Iumbricoides), and $24.0 \%$ and $112.8 \mathrm{e} / \mathrm{g}$ ( $T$. trichiura), and $\mathbf{0 . 0 \%}$ for $\boldsymbol{N}$. americanus and $S$. stercoralis. Efficacy and egg reduction rates were $\mathbf{8 4 . 6 \%}$ and $55.3 \%$ (T. trichiura), $82.0 \%$ and $52.2 \%$ (A. lumbricoides), and $\mathbf{1 0 0 . 0 \%}$ for $N$. americanus and $S$. stercoralis. These results suggest that geohelminths infections remain a serious health problem in school children in Kotto Barombi focus.

Key words: School children, geohelminth, prevalence, parasite load, albendazole, drug efficacy, Kotto Barombi, Marumba II, Cameroon.

\section{INTRODUCTION}

Soil transmitted helminths (STH) (geohelminths) infections are among the most prevalent of chronic human infections with an estimated 2 billion individuals infected worldwide (Artis, 2006). These infections are more prevalent in tropical and subtropical regions of the developing world where adequate water supply and sanitation are lacking. The major public health significance and economic impact of this group of pathogens is hard to quantify, although the WHO has estimated that more than 1000 million people world-wide are infected with one

${ }^{\star}$ Corresponding author. E-mail: njiokouf@yahoo.com. Tel: 77719631. or more of the major pathogenic species of human: Ascaris lumbricoides, Trichuris trichiura, Hookworms (Necator americanus), and that 39 million disability adjusted life years are attributed to these four Nematodes (Chan, 1997; Albonico et al., 1999; WHO, 2001).The greatest number of STH infections occur in Sub Saharan Africa where 89.9 millions of school age children are infected (Brooker, 2006a). Chronic and intense STH infections can contribute to malnutrition and iron deficiency anaemia, and can adversely affect physical and mental growth in childhood (Stephenson et al., 2000; Hotez et al., 2004; Brooker et al., 2006b).

In Cameroon, although STH infections are among the most important parasitic diseases (Tchuem et al., 2001), they are attributed less interest as compared to infections 
such as HIV/AIDS and malaria. These infections are more prevalent in the southern part of the country (Retard et al., 1991; Brooker et al., 2000; Howard et al., 2002), and are estimated to infect 5.6 million people for $A$. lumbricoides, 6.5 million for $T$. trichiura, and 2.6 million for N. americanus (Brooker et al., 2000; Tchuem Tchuente et al., 2001). These parasites co-exist in most parts of the country with other parasitic infections like schistosomiasis (Tchuem et al., 2001, 2003) causing great parasitic burden in infected children.

In an epidemiological study in Barombi villages (south west region), Couprie et al. (1986) found that the most prevalent intestinal helminths were T. trichiura (85.2\%), Necator americanus (64.1\%), A. lumbricoides (51.4\%), and Strongyloides stercoralis (9.8\%). Since then, no survey on STH has been carried out in the area. Control of these parasitic infections in Cameroon now follows the WHO recommendations (WHO, 2001) which lays emphasis on a combined control approach with schistosomiasis in areas where the two parasitic diseases coexist, especially in high risk groups (school age children), as a good means of reducing morbidity in the infected population. Control in school aged children delivered through the school system is the main intervention strategy in a community (Montresor et al., 2002, Savioli et al., 2002; Bundy et al., 2005; Brooker et al., 2006a; Kihara et al., 2007). Our study was designed to assess the current level of STH infections and impact of mass treatment with albendazole amongst school aged children, by assessing the prevalence, parasite intensity, cure rates and egg reduction rate, in order to suggest recommendations for further regional and nationwide control efforts.

\section{MATERIALS AND METHODS}

\section{Study area}

The present study was conducted in two villages (Kotto Barombi and Marumba II) of the Mbonge sub division (South West Cameroon). These villages were selected because of their high STH prevalence (Couprie et al., 1986) which co-existed with Urinary schistosomiasis (Data on shistosomiasis are mentioned elsewhere) (Moyou et al., 1987; Ratard et al., 1991; Ndamukong et al., 2000, 2001). These villages belong to the equatorial forest zone, Cameroon-type climate, with one long rainy season (March to November) and one short dry season (December to February). The total annual rainfall varies between $2000-4000 \mathrm{~mm}$ (Ratard et al., 1991). The inhabitants of this zone are farmers, practicing peasant farming.

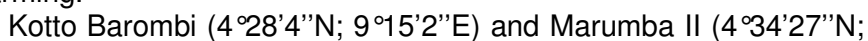
$\left.9^{\circ} 20^{\prime} 27^{\prime \prime} \mathrm{E}\right)$ are characterized by the absence of good water supply. The toilets have poor conditions and garbage piles on which children play on are found around the school premises.

\section{Study subjects}

The study was conducted from May to September 2007 (during the rainy season). Out of the 523 school children contacted from the two villages, 420 (220 girls and 200 boys) of ages between 1 and
20 years, participated in the survey. An informed consent of administrative authorities (Chief of health District and school directors, traditional leaders, and children) was obtained. A total of $277(66.0 \%)$ children came from Kotto Barombi and $143(34.0 \%)$ were from Marumba II. The sampled population was between the ages of $1-5,6-10,11-15$ and $15-20$ years.

\section{Stool collection and processing}

Prior to stool collection, children were given brief information on the disease (causes, manifestations, consequences, and diagnosis). After registration, a stool sample was collected from each volunteer in well labelled $50 \mathrm{ml}$ screw-cap vials and then transported to the General Biology laboratory (Faculty of Science) of the University of Yaounde I. The samples were analyzed using the Kato-katz faecal technique (WHO, 1991) for the identification of helminths eggs following their morphology ( $A$. lumbricoides, $T$. trichiura, and Hookworm), and larva stage (S. stercoralis) (Tanowitz et al., 1993). To minimize the measurement bias on the parasitological data, all slides were read within $24 \mathrm{~h}$ of preparation to avoid the degeneration of Hookworm eggs. All participants were subsequently treated with $600 \mathrm{mg}$ albendazole $(200 \mathrm{mg}$ for 3 days consecutively) (Tchuem Tchuente et al., 2001). Drugs distribution was supervised by a medical nurse from the District health center of the area. Control of drug efficacy was done 3 months later which is the time necessary for the adult parasite to be present in the intestine of re-infected patients (Jessika, 2005), by analyzing stool samples collected only from children who were positive during the initial survey, using the same technique mentioned above.

\section{Data analysis}

The following parameters were assessed:

1. The prevalence $(P)$, defined as the percentage of infected individuals (NP) among the total number of individuals examined (N) $(\mathrm{P}=(\mathrm{NP} / \mathrm{N}) \times 100)$ (Margolis et al., 1982);

2. The cure rate $(C R)$ which is the ratio of the difference between the number of children who were positive before treatment and those positive three months post-treatment on the number of positive cases before treatment, expressed as a percentage;

3. The parasite load which is the mean number of eggs of each parasite species per gram of stool of each patient;

4. The egg reduction rate (ERR) which is the ratio of the difference between the average parasite load before and three months after treatment on the pre-treatment parasite load, expressed as a percentage (Cure rate, parasite load, and egg reduction rate are used following Saathoff et al. (2004).

The Chi-square test was used to compare the prevalence in relation to sex, age groups, quarters, and villages while one - way ANOVA or Kruskal-Wallis tests were used to compare the parasite load in relation to sex, age groups, and villages. The Kruskal-Wallis test was used when the conditions of parametric ANOVA were not fulfilled (Sokal and Rohlf, 1981). The level of statistical significance was at $5 \%(P \leq 0.05)$.

\section{RESULTS}

\section{Prevalence before treatment}

A total of 420 out of 523 children were sampled for the survey, giving an overall participation rate of $80.3 \%$. Amongst the 420 participants, $178(42.4 \%)$ harbored at 
least one of the four helminth species recorded: $A$. lumbricoides, Trichuris trichiura, Necator americanus, Strongyloides stercoralis. Cases of single (61.2\%), double $(38.2 \%)$, and triple infection $(0.6 \%)$ were recorded in the total number of samples examined. Single infection was more prevalent for $T$. trichiura $(56.5 \%)$ and $A$. lumbricoides (39.8\%), while $N$. americanus $(1.9 \%)$ and $S$. stercoralis $(2.8 \%)$ were rarely observed. Double infection of $A$. lumbricoides - $T$. trichiura (95.6\%) dominated in the infected subjects.

A. lumbricoides (26.4\%) and T. trichura $(31.0 \%)$ were the most prevalent parasite species while $N$. americanus $(1.4 \%)$ and S. stercoralis (0.9\%) were rare (Table 1$)$. A significant difference of infection rate was observed for $A$. lumbricoides $(P=0.0001)$ and $T$. trichiura $(P=0.0005)$ between the two villages. As regards to sex, the global prevalence of $A$. lumbricoides in females $(27.3 \%)$ was higher than that in males $(23.2 \%)$ but the difference was not significant. A. lumbricoides and $T$. trichiura were found in all age groups, and were more prevalent in children below 11 years but the difference observed was not significant (Table 2).

\section{Parasite load before treatment}

The global mean parasite load for each parasite species was $6244 \mathrm{eggs} / \mathrm{g}$ of stool for A. lumbricoides, 252.4 for $T$. trichiura, and 468.0 for $N$. americanus. The parasite loads were higher in Marumba II than in Kotto Barombi with a significant difference observed for $T$. trichiura $(P=$ 0.0001).

As regards the parasite loads among sex, females were more infected by $T$. trichiura $(306.9 \mathrm{e} / \mathrm{g}$ of stool) while males were more infected by $A$. lumbricoides $(7260$ $\mathrm{e} / \mathrm{g}$ of stool). The difference observed was not significant in the entire population sampled and within each village (Table 3). There was no significant difference of parasitic load observed among age groups.

\section{Infection rates three months after treatment}

At 12 weeks after treatment, the prevalence among children re-examined (87) was $24.4 \%, 24.4 \%, 0.0 \%$, $0.0 \%$ for $A$. lumbricoides, $T$. trichiura, $N$. americanus, and $S$. stercoralis, respectively (Table 1 ). A reduction rate of $100 \%$ was observed for $N$. americanus and S. stercoralis, while that of $A$. lumbricoides $(7.2 \%)$ and $T$. trichiura $(20.8 \%)$ were low. The overall cure rates were $82.0 \%$, $84.6 \%, 100.0 \%$, and $100.0 \%$ for $A$. lumbricoides, $T$. trichiura, $N$. americanus, and $S$. stercoralis respectively (Table 4). The global parasite loads reduced considerably, with their respective ERR being 52.3\%, $55.3 \%$, and $100.0 \%$ for A. lumbricoides, T. trichiura, and $N$. americanus, respectively.

\section{DISCUSSION}

Polyparasitism of STH has long been observed in the Barombi villages, South West Cameroon (Couprie et al., 1986) with the principal parasites species being $A$. lumbricoides, $T$. trichiura, $N$. americanus, and $S$. stercoralis. The overall infection rate $(42.4 \%)$ observed in our study is quite lower than that recorded $(94.2 \%)$ by Couprie et al. (1986) in the same area, and that of Tchuem Tchuente et al. $(2001,2003)$ in Makenene $(60.0 \%)$ and Loum (90.3\%) respectively. This difference observed may be linked to past history of chemotherapy. It is likely that, the previous study was conducted when children had spent much time without taking anthelminthic treatment, what could lead to infections accumulation. Auto medication is commonly being taken at individual levels, and can probably be the reason of the low infestation rate recorded during our study. This difference could also be attributed to the difference in methodology. We used the Kato-katz method (WHO, 1991) during which only one slide was read from each sample, more adapted to mass campaign studies but less sensitive than the concentrating formol ether technique used by Couprie et al. (1986).

Similar results have been observed in previous studies in Malawi where different results were obtained when using different techniques (Phiri et al., 2000; Cameron et al., 2004). Parasitic distribution is not homogeneous and varies in relation to geographical areas as earlier observed by Ratard et al. (1991). This can explain the difference between our results and that obtained in Loum and Makenene by Tchuem Tchuente et al. (2001; 2003).

Cases of single, double and triple infections were noted with no case of infection with four parasites species as previously recorded by Couprie et al. (1986). Double infection of $A$. lumbricoides - T. trichiura (95.6\%) was the most frequent in the sampled population. This observation is obvious as the two parasites species are both transmitted by the faecal - oral route (dirty hands and contaminated food (OMS, 2006). The risk factor of $N$. americanus transmission has been shown to be linked to agricultural profession and prevalence increases with age (Couprie et al., 1986; Gandhi et al. 2001; Speare et al., 2006; Kihara et al., 2007). The low infection rate of $N$. americanus $(1.4 \%)$ obtained may be explained by the studied population group, as the survey was done exclusively on children, who do not spend too much time in farm work as adults. However, our result is different from that obtained in school children (50.9\%) and in adults $(31.7 \%)$ in Uganda (Zhang et al., 2007).

High prevalence of $A$. lumbricoides and T. trichiura, and high intensity of $T$. trichiura in females compared to males is a common occurrence in the same study area (Couprie et al., 1986), other parts of the country(Ratard et al., 1991; Tchuem Tchuente et al., 2003), and in other parts of the world (Saathoff et al., 2004). This difference can be attributed to the different pattern of soil contact, 
118 Afr. J. Environ. Sci. Technol.

Table 1. Prevalence of parasite species among Kotto, Barombi and Marumba II school children.

\begin{tabular}{llccccc}
\hline \multirow{2}{*}{ Villages } & \multirow{2}{*}{ Survey phases } & \multirow{2}{*}{ Number of children examined } & \multicolumn{4}{c}{ Number and percentage of positive children } \\
\cline { 4 - 7 } & & 277 & A. lumbricoïdes & T. Trichiura & N. americanus & S. stercoralis \\
\hline \multirow{2}{*}{ Kotto Barombi } & Before treatment & 35 & $59(17.7)$ & $64(22.1)$ & $6(2.2)$ & $4(1.4)$ \\
& After treatment & & $5(14.3)$ & $3(8.6)$ & $0(0.0)$ & $0(0.0)$ \\
\multirow{2}{*}{ Marumba II } & & 143 & $62(43.4)$ & $66(46.2)$ & $0(0.0)$ & $0(0.0)$ \\
& Before treatment & 47 & $15(36.6)$ & $17(36.2)$ & $0(0.0)$ & $0(0.0)$ \\
\cline { 3 - 7 } Total & After treatment & & & & & \\
& & 420 & $111(26.4)$ & $130(31.0)$ & $6(1.4)$ & $4(0.9)$ \\
& Before treatment & 82 & $20(24.4)$ & $20(24.4)$ & $0(0.0)$ & $0(0.0)$ \\
\hline
\end{tabular}

Table 2. Prevalence of parasite species in age groups.

\begin{tabular}{lcccccc}
\hline \multirow{2}{*}{ Villages } & \multirow{2}{*}{ Age groups } & \multirow{2}{*}{ Number of children examined } & \multicolumn{4}{c}{ Number and percentage of positive children } \\
\cline { 4 - 7 } & & & A. Iumbricoïdes & T. Trichiura & N. americanus & S. stercoralis \\
\hline Kotto Barombi & $1-5$ & 30 & $7(23.3)$ & $6(20.0)$ & $1(3.3)$ & $2(6.7)$ \\
& $6-10$ & 117 & $21(17.9)$ & $29(24.8)$ & $3(2.6)$ & $1(0.9)$ \\
& $11-15$ & 123 & $20(16.3)$ & $29(23.6)$ & $2(1.6)$ & $1(0.8)$ \\
& $16-20$ & 7 & $1(14.3)$ & $1(14.3)$ & $0(0.0)$ & $0(0.0)$ \\
Marumba II & $1-5$ & 25 & $13(52.0)$ & $12(48.0)$ & $0(0.0)$ & $0(0.0)$ \\
& $6-10$ & 85 & $39(45.9)$ & $41(48.2)$ & $0(0.0)$ & $0(0.0)$ \\
& $11-15$ & 33 & $10(30.3)$ & $13(39.4)$ & $0(0.0)$ & $0(0.0)$ \\
Total & $16-20$ & 0 & - & - & - & \\
& $1-5$ & 55 & $20(36.4)$ & $18(32.2)$ & $1(1.8)$ & $2(3.6)$ \\
& $6-10$ & 202 & $60(29.7)$ & $70(34.7)$ & $3(1.5)$ & $1(0.5)$ \\
& $11-15$ & 156 & $30(19.2)$ & $42(26.9)$ & $2(1.3)$ & $0(0.0)$ \\
& $16-20$ & 7 & $1(14.3)$ & $1(14.3)$ & $0(0.0)$ & $0(0.0)$ \\
\hline
\end{tabular}

Table 3. Average parasite load of STH species between sexes among Kotto Barombi and Marumba II' school children.

\begin{tabular}{llccc}
\hline Villages & Parasite species & Male & Female & P value \\
\hline Kotto Barombi & A. lumbricïdes & $6266(8267.4)$ & $4076(12020.8)$ & 0.47 \\
& T. trichiura & $120.7(172.5)$ & $185.5(105.5)$ & 0.72 \\
& N. americanus & $574(-)$ & $32(-)$ & - \\
Marumba II & A. lumbricoïdes & $9747(14690.1)$ & $6449(7439.8)$ & 0.27 \\
& T. trichiura & $270.7(412.1)$ & $423.5(710.5)$ & 0.78 \\
& N. americanus & - & - & - \\
Total & & & & \\
& A. lumbricoïdes & $7260(12300.4)$ & $5381(3084.3)$ & 0.37 \\
& T. trichiura & $194.6(320.6)$ & $306.9(567.8)$ & 0.57 \\
& N. americanus & $574(-)$ & $32(-)$ & - \\
\hline
\end{tabular}

Mean values are given with their standard deviation in the brackets; statistical test not done because of the very low sample size.

as it has been revealed that geophagy is more frequent in females than in males (Saathoff et al., 2002, 2004). This result is contrary to that of Hamit et al. (2008) who found that males were more parasitized because they spend much time playing than females. The low prevalence and high parasite load of $A$. lumbricoides observed in males 
Table 4. Cure rate and egg reduction rate of STH infection, three months after treatment.

\begin{tabular}{llcc}
\hline Villages & Parasite species & Cure rate & Egg reduction rate \\
\hline Kotto Barombi & A. lumbricoïdes & 89.8 & 74.74 \\
& T. trichiura & 95.5 & 31.7 \\
& N. americanus & 100 & 100 \\
\multirow{4}{*}{ Marumba II } & A. lumbricoïdes & 75.8 & 50.6 \\
& T. trichiura & 74.2 & 67.29 \\
& N. americanus & - & - \\
Total & & & \\
& A. lumbricoïdes & 82.0 & 52.2 \\
& T. trichiura & 84.6 & 55.3 \\
& N. americanus & 100 & 100 \\
\hline
\end{tabular}

than in females is contrary to results of previous studies (Tchuem et al., 2003) and it is unclear to attribute this difference to host susceptibility (Flores et al., 2001). This could partly be explained by early acquisition of the parasite in males and the number of adults female worms harbored. The significant difference of parasite load of $T$. trichiura observed in Marumba II compared to Kotto Barombi (two villages of the same geographical area) may simply be due to a difference in time acquisition of the parasite. A. Lumbricoides and $T$. trichiura were observed in all age groups and more prevalent in children below 11 years. This may likely reflect the active nature of children of this age group as young children spend much time playing, what exposes them to high risk of infection. This result also suggests that people still live in poor hygienic conditions. Our finding is in agreement with that of Couprie et al. (1986), Ratard et al.(1991), PNLSHI (2005), Rick et al. (2006), and Hamit et al . (2008).

Albendazole was quite effective against $N$. americanus and $S$. stercoralis with an egg reduction rate and cure rate of $100 \%$. The drug effect was not the same for $A$. lumbricoides and T. trichiura with an ERR of $52.3 \%$ and $55.3 \%$, and a CR of $80.0 \%$ and $84.6 \%$, respectively. The results obtained for $A$. lumbricoides differs from that of Kihara et al. (2007) who obtained an ERR and CR of $100.0 \%$ at two months post treatment. The prevalence reduction rate of $A$. lumbricoides (7.2\%) and $T$. trichiura $(20.8 \%)$ observed in our study were extremely low compared to $100.0 \%$ and $45.0 \%$ obtained respectively by Kihara et al. (2007), and $48 \%$ obtained for T. trichiura by Oqueka et al. (2005) after one dose of MDA. Albendazole acts only against the adult $A$. lumbricoides and efficacy depends on the worm burden in infected patients (Jessika, 2005). It is likely that some of the larvae form of the parasite were in the migratory phase which then developed into female adults that started laying eggs after treatment. Also, the female worm burden could have been high in patients so that there was inadequate elimination of adult worms (Jessika, 2005), what is confirmed by a high parasite load observed during pretreatment.
The low drug efficacy observed during our study for $T$. trichiura has earlier been mentioned in other endemic areas (Pascal et al., 1997; Horton, 2000; Adams et al., 2004; Speare et al., 2006; Kihara et al., 2007; Olsen et al., 2009). These results suggest that one round of MDA using albendazole may have little effect on these parasite species. Two rounds of MDA have showed little effect (Zhang et al., 2007), no effect at all (Saathoff et al., 2004), and anthelminthic resistance (Albonico et al., 2004). Treatment with a single dose of albendazole or Mebendazole has given an efficacy of almost $100.0 \%$ (Norhayati et al., 1997). Our study shows that the prevalence and parasite loads of STH infections are still high and remain a serious health problem in school children in Kotto Barombi and its neighboring villages. Also, MDA using $200 \mathrm{mg}$ of albendazole for three days has little effect in reducing the prevalence and parasite load. From these results, treatment with a single dose of albendazole or mebendazole every three months will have better effect in reducing prevalence and intensity of STH in infected children. MDA should equally be done in a combined approach with appropriate sanitation education.

\section{ACKNOWLEDGEMENTS}

We thank the headmasters and teachers of Presbyterian and Government primary schools of Kotto Barombi and Marumba II, the Kotto Barombi Chief of District Health Centre for the facilities given during this work, Mr. Daga Simon for technical assistance, Mr Nchonganyi Ignatius and Mrs Forcha Florence for their financial support and anonymous reviewers for their important suggestions.

\section{REFERENCES}

Adams VJ, Lombard CJ, Dhansay MA, Markus MB, Fincham JE (2004). Efficacy of albendazole against the whip worm Trichuris trichiura: a randomised, controlled trial. S. Afr. Med. J. 94: 972-976.

Albonico M, Cromptom DW, Savioli L (1999). Control strategies for human intestinal nematode infection. Adv. Parasitol. 42: 277-341. 
Albonico M, Engels D, Savioli L (2004). Monitoring drug efficacy and early detection of drug resistance in human soil-transmitted nematodes: a pressing public health agenda for helminths control. Int. J. Parasitol. 34: 1205-1210.

Artis D (2006). New weapons in the war on worms: Identification of putative mechanisms of immune-mediated expulsion of gastroin-testinal nematodes. Int. J. Parasitol. 36(6): 723-733.

Brooker S, Donnelly CA, Guyatt HL (2000). Estimating the number of helminthic infections in the republic of Cameroon from data on infection prevalence in schoolchildren. Bull. World Health Organization 78: 1456-1465.

Brooker S, Archie CAC, Don Bundy AP (2006a). Global epidemiology, ecology and control of soil-transmitted helminth infections. Adv. Parasitol. 62: 221-261.

Brooker S, Neal A, Stefan G, Moyeed AR, Stander J, Fleming F, Hotez PJ (2006b). Contrasting patterns in the small-scale heterogeneity of human helminth infections in urban and rural environments in Brazil. Int. J. Parasitol. 36(10-11): 1143-1151.

Bundy D, Shaeffer S, Jukes M, Beegle K, Gillespie A, Drake L, Lee seung-hee F, Hoffman AM, Jones J, Mitchell A, Wright C, Barcelona D, Camara B, Golmar C, Saviolo L, Takeuchi T, Sembene M (2005). School based Health and Nutrional Programs. In: Jamison D, Claeson M, Breman J, Meacham A., editors. Disease Control Priorities for Developing Countries. Oxford: Oxford Univ. Press, Chap. 61.

Chan MS (1997). The global burden of intestinal nematode infections fifty years on. Parasitol. Today 13: 438-443.

Cameron B, Purcell B, Shaba B, Makaula P, Perez M (2004). A national survey of the prevalence of schistosomiasis and soil tansmittd helminths in Malawi. BMC Infectious Diseases, 4: 49. Published online 16 November, 2004. doi: 10.1186/1471-2334-4-49.

Couprie B, Alilaire C, Vivind P, Daueouede S, Tchamaha R, Moyou Somo R, Ripert Ch (1986). Etude Epidémiologique des helminthiases intestinales dans quatre villages: Barombi (Cameroun-Province du Sud-ouest). Bull. de la Societé de Pathologie Exothique 79: 739-744.

Flores A, Esteban JG, Angels R, Mas-coma S (2001). Soil-transmitted helminth infections at very high altitude in Bolivia. Transaction of Royal Soc. Trop. Med. Hyg. 95: 272-277.

Gandhi NS, Jizhang C, Khoshnood K, fying X, Shanwen L, Yaoruo L, Bin Z, Haechou X, Chongjin T, Yan W, Wensen W, Dubgxing $H$, Chong C, Shuhua X, Hawdon JM, Hotez PJ (2001). Epidemiology of Necator americanus Hookworm Infection in Xiulongkan Village, Hainan Province China: High prevalence and intensity among middleaged and elderly residents. J. Parasitol. 87(4): 739-743.

Howard SC, Donnelly CA, Kabatereine NB, Rattard RC, Brooker S (2002). Spatial and intensity-dependent variations in association between multiple species helminth infections, Acta. Trop. 83: 141149.

Horton J (2000). Albendazole: a review of anthelmintic efficacy and safety in humans. Parasitology 121: 113-132. Doi: $10.1017 /$ S0031182000007290.

Hotez PJ, Brooker S, Bethony JM, Bottazzi ME, Loukas A, Xiao S (2004). Current concepts: Hookworm infection. New Engl. J. Med. 351: 799-807.

Hamit MA, Tidjani MT, Bilong Bilong CF (2008). Recent data on the prevalence of intestinal parasites in N'Djamena, Chad Republic. Afr. J. Environ. Sci. Technol. 2(12): 407- 411.

Kihara JH, Muhoho N, Njomo D, Mwobobia IK, Josyline K, Awazawa T, Amano T, Mwandawiro C (2007). Drug efficacy of praziquantel and albendazole in school children in Mwea Division, Central Province, Kenya. Acta Trop. 102: 165-171.

Jessika L (2005).

Ascariasis.http/www.stanford.edu/class/humbio103/Parasites 2005/Ascaris/J Lora-Parasite.htm.

Margolis L, Esch W, Holmes JC, Kuris AM, Schad GA (1982). The use of ecological terms in parasitology (Report of an adhoc committee of American Society of parasitologists). J. parasitol. 68(1): 131-133.

Montresor A, Cromptom DWT, Gyorkos TW, Savioli L (2002). Helminths control in school age children, a guide for managers and control programmes. WHO, Geneva.

Moyou-Somo R, Tagni Zukam D, Kouamouo J, Enyong P, Ripert C (1987). Epidemiologic and radiologic study of urinary bilharziasis in the focus of Barombi lake (Meme Dept.), Cameroon. Bull. de la Société de Pathologie Exotique 80(5): 813-825.

Ndamukong KJ, Ayuk MA, Dinga JS, Akenji TN, Ndiforchu VA, Titanji VP (2000). Infection pattern of Schistosoma haematobium in primary school children of the Kumba Health District, South-West Cameroon. Afr. J. Health Sci. 7(3-4): 98-102.

Ndamukong KJ, Ayuk MA, Dinga JS, Akenji TN, Ndiforchu VA, Titanji VP (2001). Prevalence and intensity of urinary schistosomiasis in primary school children of the kotto Barombi Health Area, Cameroon. East Afr. Med. J. 78(6): 287-289.

Norhayati M, Oothuman P, Azizi O, Fatmah MS (1997). Efficacy of single dose albendazole on the prevalence and intensity of infection of soil-transmitted helminthes in Orang Asli children in Malaysia. Southeast Asian J. Trop. Med. Public Health 28: 724.

Oqueka ST, Ismid IS, Purnomo RP, Bradley M, Fischer P (2005). Impact of two rounds of mass drug administration using diethycarbamazine combined with albendazole on the prevalence of Brugia timori and of intestinal helminths on Alor Island, Indonesia. Filarial J., 4: 5. Doi:10.1186/1475-2883-4-5.

OMS (2006). Lutte contre les parasitoses intestinales: Séries de Rapports Techni. 987: 26.

Olsen L, Namwanje H, Nejsum P, Rospstorff A, Stig MT (2009). Albendazole and mebendazole have low efficacy against Trichuris trichiura in school age children in Kabale District, Uganda. Transactions of the Royal Soc. Trop. Med. Hyg. 103: 443-446.

PNLSHI (2005). Programme National de Lutte contre la Schistosomiase et les Helminthiases intestinales au Cameroun. Plan stratégique 2005-2010 p. 92.

Phiri K, Whitty CJ, Graham SM, Sembatya-Lule G (2000). Urban/rural differences in prevalences and risk factors for intestinal helminths infection in Southern Malawi. Annals of Trop. Med. Parasitol. 94: 381 387.

Pascal M, Eric M, Peter M, Malick N, Ouma J, Saidi T (1997). A school based approach to the control of urinary schistosomiasis and intestinal helminth infections in children in Matuga, Kenya: impact of a two years chemotherapy programme on prevalence and intensity of infections. Trop. Med. Int. Health 2: 825-831.

Ratard RC, Kouemeni LE, Ekani Bessala MM (1991). Ascariasis and trichuriasis in Cameroon. 1. Transactions of the Royal Soc. Trop. Med. Hyg. 85: 84-88.

Speare R, Falatea FL, Tekaai N, Harmen S, Wayne M, Durrheim D Heukelbach $J$ (2006). Prevalence of soil-transmitted nematodes on Nukufetau, a remote Pacific island in Tuvalu. BMC Infectious Diseases, 6:110. Doi: \&0.1016/S0035-9203(02)90413-x.

Saathoff E, Olsen A, Kvalsvig JD, Geissler PW (2002). Geophagy and its association with geohelminths infection in rural schoolchildren from northern Kwazulu-Natal, South Africa. Transaction of Royal Soc. Trop. Med. Hyg. 96: 485-490.

Saathoff E, Olsen A, Kvalsvig JD, Appleton CC (2004). Patterns of geohelminths infection, impact of albendazole treatment and reinfection after treatment in school children from rural Kwazulu-Natal, South-Africa. BMC infectious Diseases, 4: 27. Published online 2004 August 13. doi:10.1186/1471-2334-4-27.

Stephenson LS, Latham MC, Ottesen EA (2000). Malnutrition and parasitic helminth infections? Parasitol. 121(Suppl): S23-S28.

Sokal RR, Rohlf FJ (1981). Biometry. $2^{\text {nd }}$ ed., Freeman \& Co., New York.

Savioli L, Stansfield S, Bundy DAP, Mitchell A, Bhatia R, Engels D, Montresor A, Neira M, Shein AM (2002). Schistosomiasis and soil transmitted helminths infections: forging control efforts. Transaction of Royal Soc. Trop. Med. Hyg. 96: 577-579.

Tanowitz HB, Weiss LM, Wittner M (1993). Diagnosis and treatment of Intestinal helminths. Gastroentrol. 1(4): 265-273.

Tchuem TLA, Southgate VR, Vercruysse J (2001). La bilharziose et les géohelminthes dans l'arrondissement de Makénéné, Province du Centre, Cameroun. Bull. de Liason et de Documentation de l'OCEAC 34(2): 19-22.

Tchuem TLA, Behnke JM, Gilbert FS, Southgate VR, Vercruysse J (2003). Polyparasitism with Schistosoma haematobium and soiltransmitted helminth infections among school children in Loum, Cameroon. Trop. Med. Int. Health 8(11): 975-986.

WHO (1991). Basic laboratory methods in medical Paraitology. World 
Health Organisation. Geneva.

WHO (2001). Control of schistosomiasis and soil transmitted helminths infections, Document A54/10. Communicable diseases, Report by the secretariat to the fifty-fourth World Health Assembly, Geneva.

Zhang Y, Koukounari A, Kabaterine N, Fleming F, Kazibwe F, Tukahebwa E, Stohard R, Webster JP, Fenwick A (2007).

Parasitological impact of 2-year preventive chemotherapy on

schistosomiasis and soil-transmitted helminth in Uganda. BMC Med.

5: 27-43. 